\title{
New Supervisory Control and Data Acquisition (SCADA) Based Fault Isolation System for Low Voltage Distribution Systems
}

\author{
Musse Mohamud Ahmed, Member, IEEE \\ ECE, Kulliyyah of Engineering IIUM, Gombak, Kuala Lumpur, Malaysia, \\ Tel: +60361964569 Fax: +60361964488 \\ Email:musse@iium.edu.my
}

\begin{abstract}
This paper proposes a new supervisory control and data acquisition (SCADA) based fault isolation system on the low voltage $(415 / 240 \mathrm{~V})$ distribution system. It presents a customized distribution automation system (DAS) for automatic operation and secure fault isolation tested in the Malaysian utility distribution system; Tenaga Nasional Berhad (TNB) distribution system. It presents the first research work on customer side automation for operating and controlling between the consumer and the substation in an automated manner. The paper focuses on the development of very secure automated fault isolation work tested to TNB distribution operating principles as the fault is detected, identified, isolated and cleared in few seconds by just clicking the mouse of laptop or desktop connected to the system. Supervisory Control and Data Acquisition (SCADA) technique has been developed and utilized to build Human Machine Interface (HMI) that provides a Graphical User Interface (GUI) functions for the engineers and technicians to monitor and control the system. Microprocessor based Remote Monitoring Devices have been used for customized software integrated to the hardware. Power Line Carrier (PLC) has been used as communication media between the consumer and the substation. As a result, complete DAS and fault isolation system has been developed for remote automated operation, cost reduction, maintenance time saving and less human intervention during faults conditions.
\end{abstract}

Keywords-Distribution Automation System (DAS); Low Voltage Distribution System; HMI\& GUI SCADA; and PLC

\section{INTRODUCTION}

This paper presents a Distribution automation system as an integrated system for the digital automation of distribution sub-station, customers and user functions (engineers \& technicians). Faults caused by over-current, earth leakage current and other disturbances create interruptions of electricity supply to the customers. The engineers and technicians have to manually locate the fault point and spend a plenty of time and this tedious work may last for extended periods of time. After the introduction of fault management, the fault is detected by energizing section by section of distribution line until the protective relay trips the feeding circuit breaker of the fault zone. These operations are mostly based on manual and automatic operations.
The advent of microprocessor and the introduction of numerical relays have improved the function of fault management system. Now it is possible to record the fault currents at the feeding distribution substations and the restoration process is also done automatically and is accelerated faster.

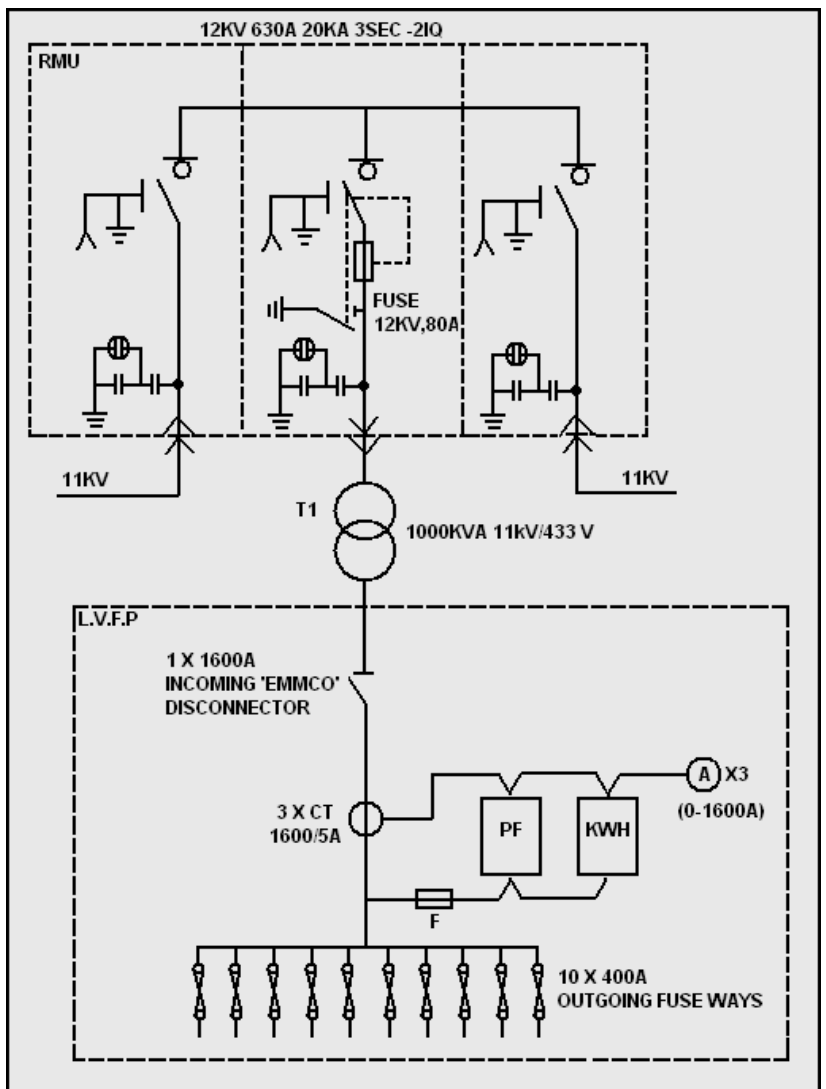

Figure1. Typical Substation

In this paper, a fault management system for low distribution automation system that is included fault detection, fault location, fault isolation and electricity supply restoration is presented. The algorithm is based on ladder logic diagram. 